\title{
Prólogo a la sexta edición
}

En casi todas las partes de la sexta edición se han hecho variaciones. Las más importantes son las siguientes : los capitulos Asfixia, Aborto inminente, y Aborto habitual se han redactado totalmente de nuevo, y los de Presentación transversal, Mola vesiculosa, Corioepitelioma y Desprendimiento prematuro de la placenta se han escrito en gran parte de nuevo.

En la Asfixia (pág. 178) se ha puesto el método de respiración artificial a sobrepresión en primer plano del tratamiento (pág. 177) y se ha llamado insistentemente la atención sobre los riesgos que corre el feto cuando se le somete a sacudidas para estimular la respiración.

A base de los modernos conocimientos (Primolut N, adrenalina, hormona folicular), se ha perfeccionado el tratamiento del Aborto inminente (pág. 458). Se ha redactado totalmente de nuevo el capitulo del Aborto habitual y, sobre todo, lo referente a los abortos habituales originados por divergencias en los grupos sanguíneos (factor Rh, sistema $\mathrm{ABO}$, antígeno de Becker, anticuerpos sesiles y otras circunstancias, pág. 461) ; asimismo se ha redactado con mayor amplitud el capítulo sobre Tetania (pág. 461) y comentado extensamente la terapéutica de estos trastornos.

Al tratar de las presentaciones transversales, se ha insistido aún más que en ediciones anteriores sobre la necesidad de diagnosticar pronto la presentación transversal y de hacer ingresar sin pérdida de tiempo la paciente en la clínica (a ser posible con la bolsa de las aguas aún íntegra). Véase las páginas 367,368 y 369 . Es todavía poco sabido que los fetos en presentación transversal, con la bolsa de las aguas todavía entera, corren un grave peligro (pág. 365). Se ha dado un mayor relieve que antes a las indicaciones de la cesárea, en caso de presentación transversal, siguiendo las orientaciones de DöDERLEIN (páginas 374, 390).

Se ha intercalado la corioepiteliosis, concepto importante desde el punto de vista práctico, entre los capítulos de Mola vesiculosa y Corioepitelioma (págs. 470, 475); se llama la atención de manera especial sobre la conveniencia de sopesar minuciosamente la indicación de extirpar el útero, sobre todo, en mujeres jóvenes, aun en presencia de "metástasis" coriales (pág. 476). En la página 468 se ha comentado la posibilidad o la probabilidad de que la mola vesiculosa tuviere por factor etiológico una infección (toxoplasmosis).

A las indicaciones (relativas) de cesárea en las presentaciones de nalgas (pág. 319) se ha agregado el parto de feto muerto anteriormente. Mientras se ha impreso esta obra, hemos llegado a la conclusión de que, para ciertos casos, sería conveniente agregar al cuadro de indicaciones a la cesárea la de desequilibrio o desproporción entre los factores sanguíneos. 
En el capitulo relativo a una duración exagerada del embarazo se han hecho resaltar los signos de alarma recomendados por RuNGE y DolfF (pág. 193). Mientras no tengamos signos aún más seguros de duración exagerada del embarazo, los de Runge y Dolff proporcionan una cierta probabilidad de que se ha rebasado la duración normal del embarazo y de que el feto corre peligro. En el tratamiento operatorio de la duración exagerada del embarazo, o bien en la provocación del parto (pág. 194), hemos descrito e ilustrado la "rotura alta de la bolsa ", recomendada por DRew-Smythe, muy difundida por BuRger en Alemania y empleada con frecuencia en nuestra clínica (pág. 197).

En dos breves capitulos nuevos, se ha descrito la histeriosis y la toxoplasmosis, trastornos importantes en relación con la Obstetricia (página 466).

Para los médicos que se inician en la Obstetricia, se ha esquematizado aún más que en ediciones anteriores el tratamiento de la placenta previa (pág. 504). En esto, así como en el tratamiento de la procidencia de brazo en las presentaciones cefálicas (pág. 444) y en el del desprendimiento prematuro de la placenta (pág. 511), se han seguido los conocidos esquemas de KraAtz. Se ha comentado (página 506) la cuestión, modernamente muy discutida, de si la hipofibrinogenemia es una de las causas posibles del desprendimiento prematuro de la placenta, y se ha resaltado (pág. 507) la necesidad de proceder a determinar reiteradamente la capacidad de coagulación de la sangre (bastan pruebas muy sencillas). Para tratar estos trastornos, que se presentan prácticamente con relativa frecuencia, se ha recomendado al médico general que, a la menor sospecha de un trastorno de la coagulación, se inyecte a la paciente, antes de trasladarla a la clínica, sulfato de protamina (pág. 513). La administración de fibrinógeno humano (Human-Fibrinogen), que preparan modernamente los establecimientos Behring, queda reservada a la clínica (página 513).

Fundados en observaciones propias, recomendamos un método especialmente sencillo, el parto por medio de valvas, para liberar operativamente al segundo gemelo en presentación longitudinal (página 423).

Al comentar la importancia de los factores sanguíneos (pág. 68), se ha mencionado la posibilidad de la punción de líquido amniótico, procedimiento que ha dado excelente resultado en la práctica (determinación prenatal de los grupos sanguíneos y manera de sentar pronóstico) (pág. 70).

Hemos sustituído algunas ilustraciones por otras nuevas.

Nuestro agradecimiento a los Doctores Hoffbauer y Bosse por la penosa labor de leer las pruebas tipográficas y por habernos dado numerosos consejos.

W. Pschyrembel 